\title{
Erratum to: Enhancement of Vortex Pinning in $\mathrm{YBa}_{2} \mathrm{Cu}_{3} \mathrm{O}_{7-\delta}-\mathrm{BaHfO}_{3}$ Superconductor-Insulator System
}

\author{
P.P. Rejith $\cdot$ S. Vidya $\cdot$ J.K. Thomas $\cdot$ Sam Solomon
}

Published online: 6 February 2013

(C) Springer Science+Business Media New York 2013

Erratum to: J Supercond Nov Magn (2012)

25:1817-1822

DOI 10.1007/s10948-012-1558-5

The original version of this article unfortunately contained mistakes. The unit mentioned for Critical current density
$\left(J_{\mathrm{C}}\right)$ should be read as $\mathrm{MA} / \mathrm{m}^{2}$ (mega ampere per metre square) instead of $\mathrm{A} / \mathrm{cm}^{2}$ and the magnitude of Flux pinning force density $\left(F_{\mathrm{p}}\right)$ should be multiplied with $10^{5}$ instead of $10^{3}$ wherever it is repeated in the manuscript including the figures and tables. This change in the unit of $J_{\mathrm{C}}$ and the magnitude of $F_{\mathrm{p}}$ will not affect any discussions in this paper.

The online version of the original article can be found under doi:10.1007/s10948-012-1558-5.

P.P. Rejith · S. Vidya · J.K. Thomas $(\bowtie)$

Electronic Materials Research Laboratory, Department of Physics,

Mar Ivanios College, Thiruvananthapuram 695 015, Kerala, India

e-mail: jkthomasemrl@yahoo.com

\section{S. Solomon}

Department of Physics, St. John's College, Anchal 691306,

Kerala, India 